\title{
Characterizing anxiety subtypes and the relationship to behavioral phenotyping in major depression: Results from the EMBARC study
}

\author{
Joseph M. Trombello ${ }^{\mathrm{a}}$, Diego A. Pizzagalli ${ }^{\mathrm{b}}$, Myrna M. Weissman ${ }^{\mathrm{c}, \mathrm{d}}$, Bruce D. Grannemann ${ }^{\mathrm{a}}$, \\ Crystal M. Cooper ${ }^{\mathrm{a}}$, Tracy L. Greer ${ }^{\mathrm{a}}$, Ashley L. Malchow ${ }^{\mathrm{a}}$, Manish K. Jha ${ }^{\mathrm{a}}$, Thomas J. Carmody ${ }^{\mathrm{a}}$, \\ Benji T. Kurian ${ }^{\mathrm{a}}$, Christian A. Webb ${ }^{\mathrm{b}}$, Daniel G. Dillon ${ }^{\mathrm{b}}$, Patrick J. McGrath ${ }^{\mathrm{c}, \mathrm{d}}$, Gerard Bruder ${ }^{\text {c,d, }}$, \\ Maurizio Fava ${ }^{\mathrm{e}}$, Ramin V. Parsey ${ }^{\mathrm{f}}$, Melvin G. McInnis ${ }^{\mathrm{g}}$, Phil Adams ${ }^{\mathrm{d}}$, Madhukar H. Trivedi ${ }^{\mathrm{a} * *}$ \\ a The University of Texas Southwestern Medical Center, Department of Psychiatry, Center for Depression Research and Clinical Care, Department of Psychiatry, Dallas, TX, \\ USA \\ ${ }^{\mathbf{b}}$ Harvard Medical School - McLean Hospital, Department of Psychiatry, Boston, MA, USA \\ c Columbia University, Department of Psychiatry, New York, NY, USA \\ ${ }^{\mathrm{d}}$ New York State Psychiatric Institute and Department of Psychiatry, College of Physicians and Surgeons of Columbia University, New York, NY, USA \\ e Massachusetts General Hospital, Department of Psychiatry, Boston, MA, USA \\ ${ }^{\mathrm{f}}$ Stony Brook University, Department of Psychiatry, Stony Brook, NY, USA \\ ${ }^{\mathrm{g}}$ University of Michigan, Department of Psychiatry, Ann Arbor, MI, USA
}

\section{A R T I C L E I N F O}

\section{Keywords:}

Anxiety

Depression

Factor analysis

Flanker Task

\begin{abstract}
A B S T R A C T
The current study aimed to characterize the multifaceted nature of anxiety in patients with major depression by evaluating distinct anxiety factors. We then related these derived anxiety factors to performance on a Flanker Task of cognitive control, in order to further validate these factors. Data were collected from 195 patients with nonpsychotic chronic or recurrent major depression or dysthymic disorder. At baseline, participants completed self-report measures of anxiety, depression, and other related symptoms (mania, suicidality) and clinicians administered a structured diagnostic interview and the Hamilton Rating Scale for Depression, including anxiety/ somatization items. Four discrete factors (State Anxiety, Panic, Neuroticism/Worry, and Restlessness/Agitation) emerged, with high degrees of internal consistency. Discriminant and convergent validity analyses also yielded findings in the expected direction. Furthermore, the neuroticism/worry factor was associated with Flanker Task interference, such that individuals higher on neuroticism/worry responded more incorrectly (yet faster) to incongruent vs. congruent trials whereas individuals higher on the fear/panic factor responded more slowly, with no accuracy effect, to the Flanker Task stimuli. These results parse anxiety into four distinct factors that encompass physiological, psychological, and cognitive components of anxiety. While state anxiety, panic and neuroticism/worry are related to existing measures of anxiety, the Restlessness/Agitation factor appears to be a unique measure of general anxious arousal. Furthermore, two factors were independently validated through the Flanker Task. These results suggest that these anxiety domains have distinct behavioral profiles and could have differential responses to distinct treatments.
\end{abstract}

\section{Introduction}

The presence of anxious symptoms in depression significantly reduces the probability of remission when treated with antidepressant medications (Fava et al., 2008). Prior research evaluating anxious symptoms in depression has most often focused on particular aspects of anxiety that align with particular anxiety disorder diagnoses. For example, many questionnaires assess symptoms associated with a specific anxiety disorder, such as Generalized Anxiety (Spitzer et al., 2006), panic disorder (Shear et al., 1997), social anxiety (Iza et al., 2014), and PTSD (Gentes et al., 2014).

While diagnostic-oriented assessment may be helpful in tracking symptoms associated with specific DSM diagnoses and the impact of treatment, there has been a push to evaluate groups of symptoms in an alternative way that will more closely align with the underlying biology and behavior associated with psychopathology. The NIMH Research Domain Criteria (RDoC) initiative (Cuthbert, 2014; Insel et al., 2010) is one approach that suggests novel conceptualizations of

\footnotetext{
* Corresponding author.

E-mail address: madhukar.trivedi@utsouthwestern.edu (M.H. Trivedi).
} 
psychopathology classification through five organizational domains.

Using diagnostic data, aspects of anxiety have been related to specific underlying biological systems that are distinct from depression (Kocovski et al., 2004). In fact, research has already identified the impact of comorbid anxiety on specific cognitive processes. For example, prior research has demonstrated how anxiety symptoms and disorders are associated with impaired cognition, attention, and behavioral task performance (Eysenck et al., 2007; Farber and Spence, 1956; Robinson et al., 2013). Using functional task-based brain imaging to probe both biological and cognitive abnormalities, Etkin and Schatzberg (2011) observed anxiety disorders to substantially modify emotional conflict regulation in the brain. While these data have elucidated the contribution of anxiety in patients with depression, further characterization of distinct factors within anxiety presentations has been lacking.

The goals of this study are (a) to use a wide selection of anxiety symptoms to determine if distinct anxiety factors can be defined and measured (b) to relate these factors to existing clinical assessments, and most importantly (c) to determine through validation, if they are relevant to performance on a behavioral task, the Flanker Task. To achieve these study aims, we utilized symptoms from six "anxiety" measures evaluating various anxiety facets (i.e., cognitive, physiological, and psychological components; anxiety disorder diagnoses). We used principal component analysis to define factors and report the relationship between these factors and other clinical measures for validation of the derived measures. We further validated these factors by associating them with performance on the Flanker Task, as prior research has revealed anxiety to negatively impact performance on this task (Chen et al., 2016; Huyser et al., 2011).

\section{Methods}

\subsection{Study design and participants}

Participants were recruited through advertising, flyers, and physician referrals for the multi-site Establishing Moderators and Biosignatures of Antidepressant Response in Clinical Care (EMBARC) study, a 16-week, placebo-controlled study to determine biological, physiological, cognitive, and genetic biomarkers of response to sertraline and bupropion (Trivedi et al., 2016). The EMBARC study recruited adult participants ages 18-65 from four sites around the United States and required participants to have recurrent or chronic single-episode major depressive disorder (MDD) or dysthymia, with the first onset before age 30. Participants were not included if they failed an antidepressant trial of sufficient dose and duration within the current episode. Key exclusion criteria included a history of inadequate response or poor tolerability to study medications; a history of psychotic or bipolar disorders; or substance dependence (except for nicotine) within the past six months or abuse within the past two months. The 16-week study consisted of two eight-week phases: at study entry, participants were randomized to receive either placebo or sertraline for eight weeks; then, at the 8th week mark, responders stayed on the initial treatment, non-responders to placebo were switched to sertraline, and non-responders to sertraline were switched to bupropion and followed for an additional eight weeks.

The study design was reviewed and approved by each site's IRB, and, before enrollment, all participants signed written informed consent after the procedures were fully explained. Participants completed a battery of self-report measures at baseline, with behavioral tasks, electroencephalographic (EEG), magnetic resonance imaging (MRI), and other assessments completed within the week prior to randomization. The data presented here include six self-report/clinician forms and behavioral data completed at the initial baseline session and/or at the first EEG session when no participant was currently receiving antidepressant medication. The data presented here encompasses 195 unmedicated participants.

\subsection{Measures}

Baseline clinician-administered measures included the Structured Clinical Interview for DSM-IV-TR (First et al., 2002) - to determine current or lifetime history of depressive and anxiety diagnoses including Panic Disorder, Social Phobia, Obsessive Compulsive Disorder, Posttraumatic Stress Disorder, Generalized Anxiety Disorder (current only), and Anxiety Disorder Not Otherwise Specified - alongside the anxious distress specifier for a major depressive episode. These items were treated as ordered, using the ratings of 1 (symptoms of the disorder were absent), 2 (sub-threshold symptoms present), and 3 (diagnostic threshold met). If there were no current diagnoses present, lifetime diagnoses were used, since, by definition, current disorders were also lifetime disorders. In addition to the six SCID anxiety disorders and the anxious distress specifier for an MDE, six items from the 17-item clinician-rated Hamilton Depression Rating Scale (Hamilton, 1960) related to anxiety (anxiety somatic, anxiety psychic, somatic general, agitation, insight, and hypochondriasis) were also used.

Self-report measures included the neuroticism subscale from the 60item NEO Five-Factor Inventory - 3 (McCrae and Costa, 2010), as well as the four items that assess for anxiety and the two items that assess for panic from the Concise Associated Symptoms Tracking Scale (Trivedi et al., 2011b). Additional measures included ten items from the Anxious Arousal subscale of a 30-item adaptation of the Mood and Anxiety Symptoms Questionnaire (Wardenaar et al., 2010), one additional item from the General Distress subscale ("I worried about a lot of things") with face-validity for anxiety, and 20 questions from the state version of the Spielberger State-Trait Anxiety Inventory (Spielberger et al., 1983), all administered before participants began their first EEG session.

Additional measures were selected for follow-up discriminant and convergent validity analyses: Anger Attacks Questionnaire (Fava et al., 1991), Altman Self-Rating Mania Scale (Altman et al., 1997), Concise Health Risk Tracking Scale (Trivedi et al., 2011a), Childhood Trauma Questionnaire (Bernstein et al., 2003), Quick Inventory of Depressive Symptoms (Rush et al., 2003), Social Adjustment Scale (Gameroff et al., 2012), and Snaith-Hamilton Anhedonia Scale (Snaith et al., 1995). All included measures are previously validated measures with strong psychometric data. In order to understand the relationship between identified factors and the clinical measures as they are used, overlapping items were not removed. All measures were scored using standard procedures.

The behavioral Flanker Task required participants to specify (via a button press) whether arrows pointed left or right; these arrows were presented alongside adjacent flankers pointed in the same (congruent) or different (incongruent) direction. Additional details about the Flanker Task's methodology have been previously described (Webb et al., 2016). Following prior research (Webb et al., 2016), main analytic variables included response time (RT) and accuracy for congruent and incongruent trials considered separately, and the Flanker interference effects, which were assessed by computing a "congruent minus incongruent" score for accuracy and an "incongruent minus congruent" score for RT, such that larger scores on both measures indicate greater interference on incongruent versus congruent trials. These effects control for individual differences in psychomotor processing speed.

\subsection{Data analysis}

The analyses used data from 200 participants who contributed baseline data to define anxiety/anxious factors based on items that ranged from current mood state (state items from the State Anxiety Inventory) to formal anxiety disorder diagnoses (from the SCID). Of the 200 participants, 195 had complete data on all items; therefore, this subset was included in analyses. Seven participants were missing data on the Flanker Task, leading to $\mathrm{N}=188$ for these analyses. The analyses were divided into four steps: (1) sample descriptives and demographics; (2) exploratory factor analysis to determine a set of factors 
that defined patient and clinician-assessed anxiety; (3) correlations to establish factors' validity with clinical measures and (4) correlations and inferential tests to establish factors' validity with the Flanker Task.

To determine the maximum number of factors to retain, both the Velicer's minimum average partial (MAP) test (Velicer, 1976) and parallel analyses (Horn, 1965) were conducted. Both methods were used since the MAP test may underestimate and the parallel analysis may overestimate the number of factors (O'Connor, 2000). These tests indicated a maximum of five factors be retained; therefore, our principal component analyses were limited to four and five-factor solutions. In order to allow for maximum separation between the measures, the factors were rotated using the varimax orthogonal rotation method. Items were assigned to the factor with its highest factor loading, to avoid any cross-loading. Furthermore, items must have met a minimum factor loading value of 0.35 (Nunnally and Bernstein, 1994). In the initial component analyses, none of the SCID item factor loadings met the 0.35 minimum criteria for loading, with ranges between 0.17 and 0.28 . Therefore, all of these items were dropped from all factor analyses.

Follow-up analysis of the factors derived from the exploratory analyses included computing item-to-item correlations and coefficient alpha values for each of the determined factors to examine internal consistency. In addition, correlations between the total scores for each of the derived anxiety factors and other clinical/behavioral measures mentioned above were conducted. Total scores were computed using the sum of the weighted items, in order to give equal weight to each of the items, since item scales were not all of the equal lengths. Pearson product-moment correlations were used to associate the anxiety factors with accuracy and RT on congruent and incongruent trials in the Flanker task, as well as the Flanker interference effects. Following prior research (Meng et al., 1992), tests for differences between the factors and correlations with Flanker effects were conducted in two steps: An overall $\mathrm{X}^{2}$ test for differences between correlated correlation coefficients, followed by pairwise comparisons if the overall test was significant $[\mathrm{p}<.05$ (two-tailed test)].

\section{Results}

\subsection{Sample characteristics}

Table 1 illustrates the sample's descriptive and demographic data. Participants' mean age was 37.16 years $(S D=13.03)$, while the mean number of years of education was $14.89(S D=2.42)$ and HAMD-17 score was $18.78(S D=4.43)$.

\subsection{Defining anxiety factors through factor analysis}

Individual items as selected above were entered into an exploratory factor analysis using varimax rotation. Results revealed five unique factors. However, the fifth factor, comprised of the lowest eigenvalue (2.49), was uninterpretable, involving items of restlessness and negative mood each comprised of individual items with loadings in opposite directions (i.e., the item "I am feeling restless, as if I have to move constantly", loaded at 0.685 , while the item from the HAM-D denoting agitation loaded at -0.341 ). For these reasons, we re-ran analyses to force four factors. All factors demonstrated appropriate loadings and high degrees of internal consistency (see Table 2) and explained very little variance of other factors (see Supplemental Fig. 1). Four factors were indicated: Immediate (state) anxiety, physiological fear response (panic) to environmental stimuli, neuroticism/worry, and agitation and restlessness.

\subsection{Intercorrelations with other baseline Clinical Characteristics}

Follow-up analyses indicated correlations with similar measures in the expected direction (see Table 3). As expected, the state/immediate
Table 1

Descriptive and demographic information for $\mathrm{N}=195$ participants.

\begin{tabular}{|c|c|c|}
\hline Variable & Frequency & Percent \\
\hline \multicolumn{3}{|l|}{ Depression Chronicity $^{a}$} \\
\hline Chronic & 94 & $48.21 \%$ \\
\hline Non-Chronic & 101 & $51.79 \%$ \\
\hline \multicolumn{3}{|l|}{ Depression Severity ${ }^{\mathrm{b}}$} \\
\hline High & 110 & $56.41 \%$ \\
\hline Low & 85 & $43.59 \%$ \\
\hline \multicolumn{3}{|l|}{ Educational Status } \\
\hline Completed Higher Education & 76 & $39.58 \%$ \\
\hline Completed Some Higher Education & 69 & $35.94 \%$ \\
\hline No Higher Education & 14 & $7.29 \%$ \\
\hline High School Diploma & 20 & $10.42 \%$ \\
\hline GED or Equivalent & 7 & $3.65 \%$ \\
\hline Did Not Graduate High School & 5 & $2.60 \%$ \\
\hline N/A & 1 & $0.52 \%$ \\
\hline \multicolumn{3}{|l|}{ Marital Status } \\
\hline Single & 116 & $60.20 \%$ \\
\hline Married & 39 & $20.21 \%$ \\
\hline Divorced & 30 & $15.54 \%$ \\
\hline Separated & 6 & $3.11 \%$ \\
\hline Widowed & 2 & $1.04 \%$ \\
\hline \multicolumn{3}{|l|}{ Hispanic or Latino Origin } \\
\hline No & 159 & $81.54 \%$ \\
\hline Yes & 36 & $18.46 \%$ \\
\hline \multicolumn{3}{|l|}{ Race } \\
\hline White & 124 & $63.59 \%$ \\
\hline Black or African-American & 45 & $23.08 \%$ \\
\hline Asian & 14 & $7.18 \%$ \\
\hline American Indian or Alaska Native & 1 & $0.51 \%$ \\
\hline Other & 11 & $5.64 \%$ \\
\hline \multicolumn{3}{|l|}{ Gender } \\
\hline Male & 66 & $33.85 \%$ \\
\hline Female & 129 & $66.15 \%$ \\
\hline \multicolumn{3}{|l|}{ Any Anxiety Disorder } \\
\hline Absent & 110 & $56.41 \%$ \\
\hline Clinically Present & 85 & $43.59 \%$ \\
\hline \multicolumn{3}{|l|}{ Anxiety NOS } \\
\hline Absent & 173 & $94.54 \%$ \\
\hline Clinically Present & 10 & $5.46 \%$ \\
\hline \multicolumn{3}{|l|}{ Generalized Anxiety Disorder } \\
\hline Absent & 163 & $83.59 \%$ \\
\hline Sub-clinically Present & 8 & $4.10 \%$ \\
\hline Clinically Present & 24 & $12.31 \%$ \\
\hline \multicolumn{3}{|l|}{ Obsessive Compulsive Disorder } \\
\hline Absent & 181 & $93.30 \%$ \\
\hline Sub-clinically Present & 8 & $4.12 \%$ \\
\hline Clinically Present & 5 & $2.58 \%$ \\
\hline \multicolumn{3}{|l|}{ Panic Disorder } \\
\hline Absent & 161 & $83.42 \%$ \\
\hline Sub-clinically Present & 15 & $7.77 \%$ \\
\hline Clinically Present & 17 & $8.81 \%$ \\
\hline \multicolumn{3}{|l|}{ Specific Phobia } \\
\hline Absent & 148 & $75.90 \%$ \\
\hline Sub-clinically Present & 12 & $6.15 \%$ \\
\hline Clinically Present & 35 & $17.95 \%$ \\
\hline \multicolumn{3}{|l|}{ PTSD } \\
\hline Absent & 165 & $84.62 \%$ \\
\hline Sub-clinically Present & 14 & $7.18 \%$ \\
\hline Clinically Present & 16 & $8.21 \%$ \\
\hline
\end{tabular}

Note. " = "Chronic" indicates individuals from the SCID whose depression history and course was deemed chronic, with only one or two, if any, well periods; while non-chronic indicates individuals with a single episode, recurrent, or chronic with multiple well episodes. ${ }^{\mathrm{b}}=$ "High severity" denotes individuals with a HAM-D $17 \geq 20$, while "low severity" denotes individuals with a HAM-D $17<20$. Finally, for all variables where levels do not add up to 195 , the differences indicate missing values.

anxiety factor was nearly perfectly correlated with the State Anxiety Index from the State-Trait Anxiety Index but also showed medium-tohigh correlations with the anxiety/somatization factor from the Hamilton Depression Rating Scale, the General Distress subscale from the Mood and Anxiety Symptom Questionnaire, and neuroticism. The panic or fear response factor was nearly perfectly correlated with the Anxious 
Table 2

Factor loadings and additional psychometric information for four anxiety factors.

\begin{tabular}{|c|c|c|c|c|c|c|}
\hline Measure & Item No. & Item Description & $\begin{array}{l}\text { Immediate (state) } \\
\text { Anxiety }\end{array}$ & $\begin{array}{l}\text { Fear Response (panic) to } \\
\text { Environmental Stimuli }\end{array}$ & $\begin{array}{l}\text { Neuroticism/ } \\
\text { Worry }\end{array}$ & $\begin{array}{l}\text { Agitation and } \\
\text { Restlessness }\end{array}$ \\
\hline STAI & 10 & I feel comfortable & -0.792 & & & \\
\hline STAI & 2 & I feel secure & -0.780 & & & \\
\hline STAI & 16 & I feel content & -0.764 & & & \\
\hline STAI & 5 & I feel at ease & -0.751 & & & \\
\hline STAI & 1 & I feel calm & -0.725 & & & \\
\hline STAI & 15 & I am relaxed & -0.714 & & & \\
\hline STAI & 20 & I feel pleasant & -0.690 & & & \\
\hline STAI & 19 & I feel steady & -0.687 & & & \\
\hline STAI & 11 & I feel self-confident & -0.662 & & & \\
\hline STAI & 8 & I feel satisfied & -0.635 & & & \\
\hline STAI & 4 & I feel strained & 0.671 & & & \\
\hline STAI & 7 & $\begin{array}{l}\text { I am presently worrying over possible } \\
\text { misfortunes }\end{array}$ & 0.626 & & & \\
\hline STAI & 6 & I feel upset & 0.617 & & & \\
\hline STAI & 3 & I am tense & 0.597 & & & 0.327 \\
\hline STAI & 17 & I am worried & 0.594 & & & \\
\hline STAI & 18 & I feel confused & 0.578 & & 0.336 & \\
\hline STAI & 9 & I feel frightened & 0.556 & & & \\
\hline STAI & 12 & I feel nervous & 0.534 & & & 0.338 \\
\hline STAI & 13 & I am jittery & 0.465 & & & 0.314 \\
\hline STAI & 14 & I feel indecisive & 0.436 & & & \\
\hline MASQ-D30 & 27 & My heart was racing or pounding & & 0.718 & & \\
\hline MASQ-D30 & 21 & I was short of breath & & 0.694 & & \\
\hline MASQ-D30 & 18 & I had pain in my chest & & 0.628 & & \\
\hline MASQ-D30 & 8 & I felt dizzy or light-headed & & 0.619 & & \\
\hline MASQ-D30 & 15 & I was trembling or shaking & & 0.595 & & \\
\hline CAST & 12 & I can feel my heart racing & & 0.566 & & \\
\hline CAST & 3 & $\begin{array}{l}\text { I feel as if I am going to have a heart } \\
\text { attack }\end{array}$ & & 0.539 & & \\
\hline MASQ-D30 & 30 & I had trouble swallowing & & 0.484 & & \\
\hline MASQ-D30 & 20 & I had hot or cold spells & & 0.483 & & \\
\hline HAM-D & 11 & Anxiety, somatic & & 0.453 & & \\
\hline MASQ-D30 & 24 & My muscles were tense or sore & & 0.428 & & \\
\hline MASQ-D30 & 5 & I felt nauseous & & 0.420 & & \\
\hline MASQ-D30 & 2 & I was startled easily & & 0.401 & & \\
\hline NEO-FFI-3 & 26 & Sometimes I feel completely worthless. & & & 0.643 & \\
\hline NEO-FFI-3 & 41 & $\begin{array}{l}\text { Too often, when things go wrong, I get } \\
\text { discouraged and feel like giving up }\end{array}$ & & & 0.612 & \\
\hline NEO-FFI-3 & 6 & At times I have felt bitter and resentful. & & & 0.548 & \\
\hline NEO-FFI-3 & 51 & $\begin{array}{l}\text { I often feel helpless and want someone } \\
\text { else to solve my problems }\end{array}$ & & & 0.517 & \\
\hline NEO-FFI-3 & 36 & $\begin{array}{l}\text { I often get angry at the way people treat } \\
\text { me }\end{array}$ & & & 0.495 & \\
\hline NEO-FFI-3 & 56 & $\begin{array}{l}\text { At times I have been so ashamed I just } \\
\text { wanted to hide }\end{array}$ & & & 0.490 & \\
\hline NEO-FFI-3 & 11 & $\begin{array}{l}\text { When I'm under a great deal of stress, } \\
\text { sometimes I feel like I'm going to pieces. }\end{array}$ & & & 0.479 & 0.338 \\
\hline NEO-FFI-3 & 16 & I rarely feel lonely or blue & & & -0.457 & \\
\hline NEO-FFI-3 & 31 & I rarely feel fearful or anxious. & & & -0.440 & -0.410 \\
\hline MASQ-D30 & 28 & I worried about a lot of things & & & 0.416 & \\
\hline NEO-FFI-3 & 1 & I am not a worrier. & & & -0.401 & \\
\hline CAST & 15 & I cannot sit still & & & & 0.679 \\
\hline CAST & 6 & $\begin{array}{l}\text { I am feeling restless, as if I have to move } \\
\text { constantly }\end{array}$ & & & & 0.654 \\
\hline CAST & 11 & I feel very tense and I cannot relax. & & & & 0.651 \\
\hline NEO-FFI-3 & 21 & I often feel tense and jittery. & & & & 0.571 \\
\hline CAST & 1 & I feel anxious all the time & & & 0.303 & 0.550 \\
\hline * HAM-D & 20 & Anxiety Psychic & & & & 0.317 \\
\hline NEO-FFI-3 & 46 & I am seldom sad or depressed & & & & 0.392 \\
\hline Eigenvalue & & & 9.11 & 4.78 & 3.75 & 3.59 \\
\hline Percent Variance & & & 16.56 & 8.69 & 6.82 & 6.53 \\
\hline \multicolumn{7}{|l|}{ Explained } \\
\hline Coefficient Alpha & & & 0.92 & 0.82 & 0.75 & 0.63 \\
\hline
\end{tabular}

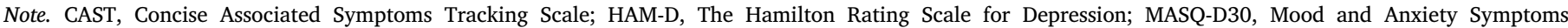

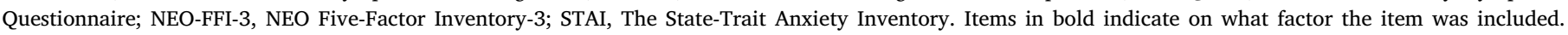
* $=$ item not included in any factor, due to loading below 0.35 .

Arousal subscale from the Mood and Anxiety Symptom Questionnaire but also demonstrated medium-to-high correlations with the 10-item General Distress subscale from the Mood and Anxiety Symptom Questionnaire. As the state/immediate anxiety factor was wholly comprised of the State Anxiety Index, it measures exclusively symptoms assessed by this instrument.

The neuroticism and worry factor was, as expected, nearly perfectly correlated with neuroticism but also demonstrated high correlations with General Distress and with the propensity for suicidality subscale of the Concise Health Risk Tracking scale, which denotes low levels of 
Table 3

Intercorrelations between each of the four factors and additional items/measures for convergent and discriminant validity.

\begin{tabular}{|c|c|c|c|c|}
\hline Variables & Immediate/State Anxiety Factor & Fear (Panic) Factor & Neuroticism and Worry Factor & Restlessness and Agitation Factor \\
\hline State Anxiety Factor & - & & & \\
\hline \multirow[t]{2}{*}{ Panic Factor } & & - & & \\
\hline & $.27^{* * *}$ & & & \\
\hline \multirow[t]{2}{*}{ Neuroticism and Worry Factor } & & & - & \\
\hline & $.37 * * *$ & $.23^{* *}$ & & \\
\hline \multirow[t]{2}{*}{ Restlessness/Agitation Factor } & & & & - \\
\hline & $.36^{* * *}$ & $.40^{* * *}$ & $.26^{* * *}$ & \\
\hline \multicolumn{5}{|l|}{ AAQ Score } \\
\hline & .07 & $.26^{* * *}$ & $.15^{*}$ & $.36^{* * *}$ \\
\hline \multicolumn{5}{|l|}{ ASRM Score } \\
\hline & .00 & .04 & -.06 & $.16^{*}$ \\
\hline \multicolumn{5}{|l|}{ CAST Total } \\
\hline & $.29 * * *$ & $.49 * * *$ & $.26^{* * *}$ & $.78^{* * *}$ \\
\hline \multicolumn{5}{|l|}{ CAST Anxiety } \\
\hline & $.33^{* * *}$ & $.40 * * *$ & $.25^{* * *}$ & $.94 * * *$ \\
\hline \multicolumn{5}{|l|}{ CAST Insomnia } \\
\hline & .12 & .05 & .10 & $.20 * *$ \\
\hline \multicolumn{5}{|l|}{ CAST Irritability } \\
\hline & $.29^{* * *}$ & $.41 * * *$ & $.35^{* * *}$ & $.58^{* * *}$ \\
\hline \multicolumn{5}{|l|}{ CAST Mania } \\
\hline & -.09 & .06 & $-.17^{*}$ & $.26^{* * *}$ \\
\hline \multicolumn{5}{|l|}{ CAST Panic } \\
\hline & $.20 * *$ & $.58^{* * *}$ & $.17^{*}$ & $.27^{* * *}$ \\
\hline \multicolumn{5}{|l|}{ CHRT Propensity Score } \\
\hline & $.28^{* * *}$ & $.22^{* *}$ & $.53^{* * *}$ & $.24 * * *$ \\
\hline \multicolumn{5}{|l|}{ CHRT Risk Score } \\
\hline & $.17^{* *}$ & $.29 * * *$ & $.26^{* * *}$ & $.35^{* * *}$ \\
\hline \multicolumn{5}{|l|}{ CTQ Emotional Abuse } \\
\hline & $.19^{* *}$ & $.21 * *$ & $.26^{* * *}$ & $.18^{*}$ \\
\hline CTQ Emotional Neglect & & & & \\
\hline & $.17^{*}$ & $.19 * *$ & $.16^{*}$ & $.18 *$ \\
\hline CTQ Physical Abuse & & & & \\
\hline & $.14 *$ & $.13^{*}$ & .02 & .09 \\
\hline CTQ Physical Neglect & & & & \\
\hline & $.29 * * *$ & $.24 * * *$ & $.16^{*}$ & $.23^{* *}$ \\
\hline CTQ Sexual Abuse & & & & \\
\hline & .08 & $.16^{*}$ & $.20^{* *}$ & -.02 \\
\hline HAM-D 17 item & & & & \\
\hline & $.38^{* * *}$ & $.32^{* * *}$ & 14 & $24 * * *$ \\
\hline MASQ Anxious Arousal & & & & \\
\hline & $.25^{* * *}$ & $.96^{* * *}$ & $.21^{* *}$ & $.36^{* * *}$ \\
\hline MASQ Anhedonic Depression & & & & \\
\hline & $.29^{* * *}$ & .04 & $.27^{* * *}$ & .00 \\
\hline MASQ General Distress & & & & \\
\hline & $.39 * * *$ & $.38 * * *$ & $.62^{* * *}$ & $.23^{* * *}$ \\
\hline NEO-FFI-3 Agreeableness & & & & \\
\hline & -.04 & $-.12^{*}$ & $-.23^{* * *}$ & $-.22^{* *}$ \\
\hline NEO-FFI-3 Conscientiousness & & & & \\
\hline & $-.14^{*}$ & .05 & $-.41^{* * *}$ & .03 \\
\hline NEO-FFI-3 Extraversion & & & & \\
\hline & $-.12^{*}$ & $.19^{* *}$ & $-.26^{* * *}$ & .11 \\
\hline NEO-FFI-3 Neuroticism & & & & \\
\hline & $.34 * * *$ & $.21^{* *}$ & $.96^{* * *}$ & $.23^{* *}$ \\
\hline NEO-FFI-3 Openness & & & & \\
\hline & -.09 & $.18^{*}$ & .01 & -.08 \\
\hline QIDS Total & & & & \\
\hline & $.29^{* * *}$ & $.32^{* * *}$ & $.24 * * *$ & $.22^{* *}$ \\
\hline SAS Mean & & & & \\
\hline & $.24^{* * *}$ & $.17^{*}$ & $.37^{* * *}$ & $.13^{*}$ \\
\hline SHAPS Total & & & & \\
\hline & $.18^{* *}$ & $.18^{* *}$ & .14 & .01 \\
\hline STAI Score & & & & \\
\hline & $.99^{* * *}$ & $.28 * * *$ & $.40^{* * *}$ & $.38 * * *$ \\
\hline Any Anxiety Disorder & & & & \\
\hline & $.15^{*}$ & $.16^{*}$ & .04 & $.22^{* *}$ \\
\hline
\end{tabular}

Note. ${ }^{*} p<.05, * * p<.01, * * * p<.001$.

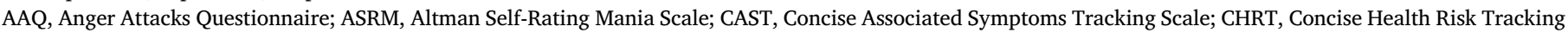

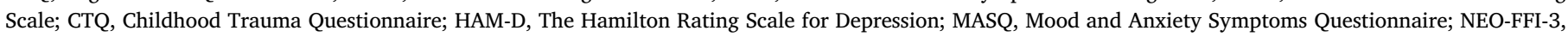

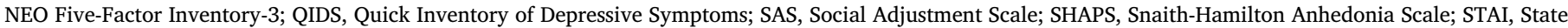
Anxiety Inventory. 
social support and high degrees of hopelessness, and a medium correlation with the Social Adjustment Scale. Finally, the agitation and restlessness factor demonstrated a medium correlation with the Anger Attacks Questionnaire, Anxious Arousal subscale of the Mood and Anxiety Symptom Questionnaire, and the risk subscale of the Concise Health Risk Tracking Scale, which denotes active suicidal ideation. These correlations are logical, given this factor's emphasis on agitation and restlessness. Of particular note, generally medium or small-tomedium correlations were observed between the factors. Factors were generally correlated with the presence of any anxiety disorder from the SCID, but only at a small-to-nonsignificant level. Finally, discriminant validity was established by the presence of nonsignificant or small degrees of correlations between many of the factors and unrelated symptom profiles, such as anhedonia and mania, which are more characteristic of unipolar/bipolar depressive disorders rather than anxiety disorders/symptoms.

\subsection{Validation with Flanker Task}

When considering Flanker data, RT was faster and accuracy higher, on congruent (M_RT: $373.53 \mathrm{~ms}, S_{\_}$RT: $56.69 \mathrm{~ms}$, accuracy: $96.41 \%$ ) as compared to incongruent trials (M_RT: $434.19 \mathrm{~ms}, S D_{-} \mathrm{RT}$ : $70.57 \mathrm{~ms}$, accuracy: $75.20 \%$ ), indicating that the task elicited the intended effects. Additional results indicated that the panic factor was associated with increased RT (slower performance), and the neuroticism/worry factor was associated with decreased RT (faster performance), in both congruent and incongruent trials (Table 4). State Anxiety and Restlessness/ Agitation were consistently unassociated with Flanker Task RT or accuracy. Only the neuroticism/worry factor was significantly associated with Flanker interference effects on RT and accuracy. Specifically, higher scores on neuroticism/worry were associated with greater interference effect on accuracy but reduced interference effect on RT (Fig. 1). Thus, individuals with greater neuroticism/worry made more mistakes in response to incongruent vs. congruent trials but without showing the expected slowing when responding to incongruent vs. congruent trials.

To further elucidate these findings, the overall test for differences between the size of correlation for the four factors and the Flanker interference (accuracy) was not significant $\left(X^{2}(3)=5.58, p>.05\right)$. However, the overall test was statistically significant for the Flanker interference on RT $\left(X^{2}(3)=9.97, p<.05\right)$. Pairwise tests indicated the correlation between the neuroticism/worry factor and Flanker interference (RT) was significantly greater than that between Flanker interference RT and all other factors (Immediate Anxiety: $\mathrm{Z}=2.38$, Panic: $Z=2.86$, Restlessness and Agitation: $Z=2.91$ ). These results indicate that only the neuroticism/worry factor was significantly related to Flanker Task interference, and, in the case of RT, significantly more so than all other factors.

\section{Discussion}

This study provides evidence for four distinct anxiety symptom factors - current emotional response, physiological fear/panic response to environmental stimuli, neuroticism/worry, and agitation/restlessness in a large sample of outpatients with depression. Convergent validity of these factors was well-established through intercorrelations with other clinical measures of anxiety (panic/anxiety; general distress; anxious arousal; neuroticism, state anxiety). As a further test of validity, we determined that the fear/panic and neuroticism/worry factors were associated with performance on the Flanker Task, such that higher scores on fear/panic were associated with increased response time (RT), and that higher scores on neuroticism/worry were associated with reduced RT and impaired task accuracy. No relationship on Flanker Task RT or accuracy occurred among the State Anxiety and Restlessness/ Agitation factors, further suggesting differential effects and also demonstrating a unique finding of how the Flanker Task was associated with some subtypes of anxiety but not others. Prior EMBARC-study research (Webb et al., 2016) determined that neuroticism - as assessed by the NEO neuroticism subscale - was not significantly correlated with Flanker task performance; the different results might be due to the divergent ways in which neuroticism/worry was defined in the Webb study as opposed to ours, and especially due the increase in sample size (and therefore power) in our study.

Most importantly, these results suggest that there is not a single unidimensional symptom factor that can define anxiety. Our anxiety factors describe unique components of anxiety among depressed outpatients, including immediate state anxiety; physiological components of anxiety akin to panic; cognitive aspects of anxiety, including worry, fear, and helplessness; and psychomotor and cognitive restlessness/ agitation. Of particular interest, state anxiety factor was fully explained by a single measure: The State Anxiety Inventory. Furthermore, two of these factors, panic/fear, and neuroticism/worry, were associated with performance on the Flanker Task, which measured response inhibition and cognitive control. Taken together, our results indicate that using only a single measure to capture anxiety would limit examination of the variability of how anxiety among depressed outpatients is experienced and demonstrates how components of anxiety among depressed outpatients are differentially associated with impaired cognitive control. It is important to note very high correlations were observed between the state anxiety factor and the STAI; between the panic/fear factor and the Anxious Arousal subscale from the MASQ, and between the neuroticism/worry factor and the neuroticism subscale of the NEO. Therefore, clinicians may consider using the single measures referenced above for the sake of clinical utility and parsimony.

One major advantage of our study lies in the use of self-report, clinician-rated, and behavioral data (for validation purposes). No diagnostic anxiety disorder from the SCID loaded on any specific factor. Although eligibility criteria excluded participants with current primary anxiety diagnoses, $43.6 \%$ of patients were diagnosed with a current or lifetime anxiety disorder diagnosis. Therefore, these findings suggest that specific DSM-defined anxiety disorders may represent something distinct from the four anxiety factors identified in our study. Anxiety disorders per diagnostic criteria are inherently heterogeneous, with any two people meeting criteria for the same disorder potentially having vastly different symptom profiles.

Another important study finding was linking discrete anxiety symptom factors and differential patterns of response in the Flanker Task, whereby some factors were not associated with task accuracy or RT, while others were. Specifically, neuroticism/worry was uniquely associated with Flanker Task interference (i.e., greater accuracy but reduced RT interference, perhaps due to a speed-accuracy trade-off), while fear/panic was associated with slower RT, and neuroticism/ worry with faster RT, further differentiating these factors. These results suggest heterogeneous subgroups of anxiety within depressed outpatients, and that these subgroups might be associated with different underlying biology - a question for future research - with differential effects on task performance.

By determining unique factors that capture physiological and psychological anxiety, the current study is in line with prior research focused exclusively on anxiety (Lang et al., 2000), yet extends this research on anxiety classification into a sample of outpatients with primary depression. We predict that physiological and psychological forms of anxiety will differentially manifest in other forms of behavior beyond the current study; therefore, our findings suggest areas for future research. In subsequent research, we plan (a) to test our four anxiety factors alongside both resting and task-based neuroimaging data to better understand the differences in physiological and brain systems implicated in each of these components of anxiety and (b) to analyze whether depression treatment outcomes are predicted by baseline levels of various anxiety factors. Such research may situate these distinct anxiety components closer to the concept of endophenotypes (Insel and Cuthbert, 2009). 
Table 4

Correlations between each of the four factors and both RT and accuracy from the Flanker Task $(\mathrm{N}=188)$.

\begin{tabular}{|c|c|c|c|c|}
\hline Variables & Immediate/State Anxiety Factor & Fear (Panic) Factor & Neuroticism and Worry Factor & Restlessness and Agitation Factor \\
\hline Mean RT on congruent trials ${ }^{\mathrm{a}}$ & $-.14+$ & $.17^{*}$ & $-.16^{*}$ & .03 \\
\hline Accuracy on congruent trials ${ }^{\mathrm{b}}$ & .07 & -.02 & .06 & .01 \\
\hline Mean RT on incongruent trials & -.07 & $.15^{*}$ & $-.19 * *$ & .04 \\
\hline Accuracy on incongruent trials & .08 & .03 & -.08 & .02 \\
\hline Flanker interference $(\mathrm{RT})^{\mathrm{c}}$ & .07 & .04 & $-.23^{* *}$ & .03 \\
\hline Flanker interference (accuracy) ${ }^{\mathrm{d}}$ & -.01 & -.03 & $.19^{*}$ & .04 \\
\hline
\end{tabular}

Note. $+\mathrm{p}<.10,{ }^{*} \mathrm{p}<.05,{ }^{* *} \mathrm{p}<.01$

a Calculated in $\mathrm{ms}$.

b Computed as percent correct responses.

c Flanker interference (RT) = RT(incongruent) - RT(congruent).

d Flanker interference (accuracy) effect = Accuracy(congruent) - Accuracy(incongruent).

There are a number of strengths of the current study, including a relatively large sample size across several geographically-diverse sites within the United States, advanced analytic techniques, and the inclusion of well-validated clinician and self-report measures of anxiety. The main limitation is the exclusion of participants with primary anxiety disorders; however, almost $44 \%$ of participants had either a current or a lifetime anxiety disorder diagnosis based on a structured clinical interview. Additional limitations include the inclusion of particular measures at time points where anxiety may already be relatively higher (i.e., before an EEG), the use of incomplete measures (i.e., only the state subscale of the State-Trait Anxiety Inventory), and the facts that no biological measures were included and that only participants with major depressive disorder and/or dysthymia were included, limiting the ability to take a fully RDoC-based, transdiagnostic framework to this study. Nonetheless, the current study capitalizes on a range of measures of varying types and administration procedures in order to more comprehensively investigate the nature of anxiety than traditional research that has relied only on single measures of anxiety, or only anxiety disorder diagnoses.

Our findings support an approach to anxiety that examines anxiety not as distinct disorders nor as unidimensional, but instead as represented through separate dimensions encoding cognitive, physiological, and psychological components, as assessed by several self-report and clinician-assessed instruments. Future research should associate these factors with genetic, physiological, and additional behavioral data beyond those explored in this manuscript, as well as antidepressant treatment outcomes. Future research should also explore whether these anxiety subgroups might serve as antidepressant treatment moderators.

\section{Role of funding}

The EMBARC study was supported by the National Institute of Mental Health of the National Institutes of Health under award numbers U01MH092221 (Trivedi, M.H.) and U01MH092250 (McGrath, P.J.,
Parsey, R.V., Weissman, M.M.). The content is solely the responsibility of the authors and does not necessarily represent the official views of the National Institutes of Health. Valeant Pharmaceuticals donated the Wellbutrin XL used in the study. This work was supported by the EMBARC National Coordinating Center at UT Southwestern Medical Center, Madhukar H. Trivedi, M.D., Coordinating PI, and the Data Center at Columbia and Stony Brook Universities.

\section{Disclosures}

Bruce Grannemann, Dr. Crystal Cooper, Ashley Malchow, Dr. Manish Jha, Dr. Thomas Carmody, Dr. Christian Webb, Dr. Gerard Bruder, Dr. Ramin Parsey, Dr. Melvin McInnis and Dr. Phil Adams do not report any personal, financial or professional relationships or conflicting interests. Dr. Trombello currently owns stock in Merck and Gilead Sciences and within the past 36 months previously owned stock in Johnson \& Johnson. Over the past 3 years, Dr. Diego Pizzagalli has received consulting fees from Akili Interactive Labs, BlackThorn Therapeutics, Pfizer and Posit Science, for activities unrelated to the current research. Dr. Benji Kurian has received research grant support from the following organizations: Targacept, Inc., Pfizer, Inc., Johnson \& Johnson, Evotec, Rexahn, Naurex, Forest Pharmaceuticals and the National Institute of Mental Health (NIMH). Dr. Daniel Dillon has been an advisor/consultant for Pfizer Inc., on activities unrelated to the current project. Dr. Pat McGrath has received funding from the National Institute of Mental Health, New York State Department of Mental Hygiene, Research Foundation for Mental Hygiene (New York State), Forest Research Laboratories, Sunovion Pharmaceuticals, and Naurex Pharmaceuticals (now Allergan). Dr. Maurizio Fava has received research support from Abbott Laboratories; Acadia Pharmaceuticals; Alkermes, Inc.; American Cyanamid; Aspect Medical Systems; AstraZeneca; Avanir Pharmaceuticals; AXSOME Therapeutics; BioResearch; BrainCells Inc.; Bristol-Myers Squibb; CeNeRx BioPharma; Cephalon; Cerecor; Clintara, LLC; Covance; Covidien; Eli Lilly and
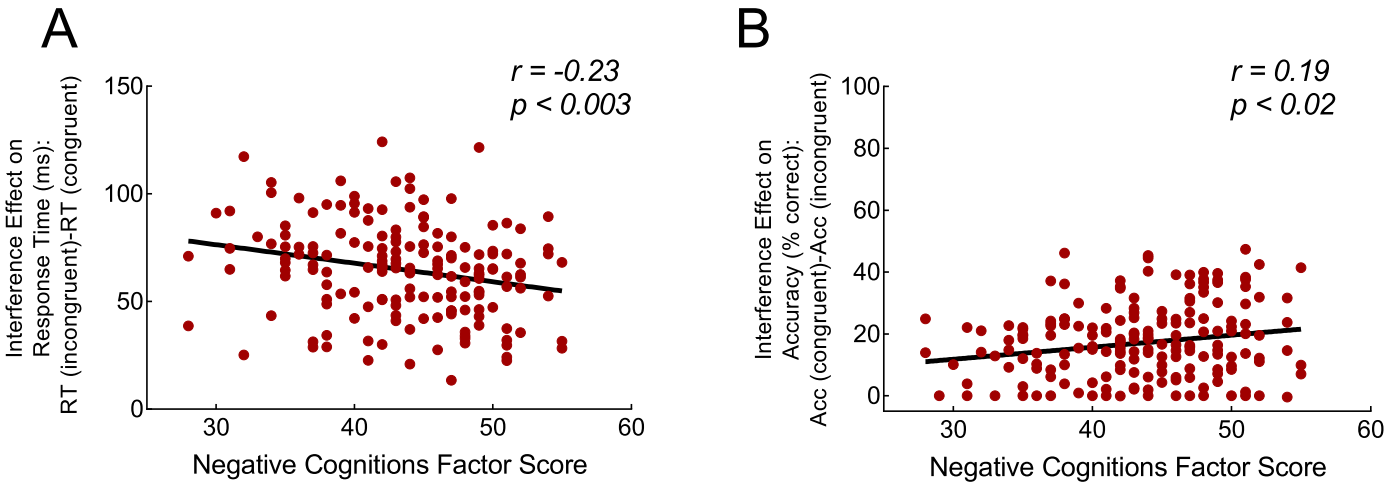

Fig. 1. Correlations between neuroticism/worry factor score and Flanker interference effects when considering (A) response time and (B) accuracy. 
Company; EnVivo Pharmaceuticals, Inc.; Euthymics Bioscience, Inc.; Forest Pharmaceuticals, Inc.; FORUM Pharmaceuticals; Ganeden Biotech, Inc.; GlaxoSmithKline; Harvard Clinical Research Institute; Hoffman-LaRoche; Icon Clinical Research; i3 Innovus/Ingenix; Janssen R\&D, LLC; Jed Foundation; Johnson \& Johnson Pharmaceutical Research \& Development; Lichtwer Pharma GmbH; Lorex Pharmaceuticals; Lundbeck Inc.; MedAvante; Methylation Sciences Inc; National Alliance for Research on Schizophrenia \& Depression (NARSAD); National Center for Complementary and Alternative Medicine (NCCAM);National Coordinating Center for Integrated Medicine (NiiCM); National Institute of Drug Abuse (NIDA); National Institute of Mental Health (NIMH); Neuralstem, Inc.; NeuroRx; Novartis AG; Organon Pharmaceuticals; PamLab, LLC.; Pfizer Inc.; PharmaciaUpjohn; Pharmaceutical Research Associates., Inc.; Pharmavite LLC; PharmoRx Therapeutics; Photothera; Reckitt Benckiser; Roche Pharmaceuticals; RCT Logic, LLC (formerly Clinical Trials Solutions, LLC); Sanofi-Aventis US LLC; Shire; Solvay Pharmaceuticals, Inc.; Stanley Medical Research Institute (SMRI); Synthelabo; Takeda Pharmaceuticals; Tal Medical; VistaGen); Wyeth-Ayerst Laboratories; he has served as advisor or consultant to Abbott Laboratories; Acadia; Affectis Pharmaceuticals AG; Alkermes, Inc.; Amarin Pharma Inc.; Aspect Medical Systems; AstraZeneca; Auspex Pharmaceuticals; Avanir Pharmaceuticals; AXSOME Therapeutics; Bayer AG; Best Practice Project Management, Inc.; Biogen; BioMarin Pharmaceuticals, Inc.; Biovail Corporation; BrainCells Inc; Bristol-Myers Squibb; CeNeRx BioPharma; Cephalon, Inc.; Cerecor; CNS Response, Inc.; Compellis Pharmaceuticals; Cypress Pharmaceutical, Inc.; DiagnoSearch Life Sciences (P) Ltd.; Dinippon Sumitomo Pharma Co. Inc.; Dov Pharmaceuticals, Inc.; Edgemont Pharmaceuticals, Inc.; Eisai Inc.; Eli Lilly and Company; EnVivo Pharmaceuticals, Inc.; ePharmaSolutions; EPIX Pharmaceuticals, Inc.; Euthymics Bioscience, Inc.; Fabre-Kramer Pharmaceuticals, Inc.; Forest Pharmaceuticals, Inc.; Forum Pharmaceuticals; GenOmind, LLC; GlaxoSmithKline; Grunenthal $\mathrm{GmbH}$; Indivior; i3 Innovus/Ingenis; Intracellular; Janssen Pharmaceutica; Jazz Pharmaceuticals, Inc.; Johnson \& Johnson Pharmaceutical Research \& Development, LLC; Knoll Pharmaceuticals Corp.; Labopharm Inc.; Lorex Pharmaceuticals; Lundbeck Inc.; MedAvante, Inc.; Merck \& Co., Inc.; MSI Methylation Sciences, Inc.; Naurex, Inc.; Nestle Health Sciences; Neuralstem, Inc.; Neuronetics, Inc.; NextWave Pharmaceuticals; Novartis AG;Nutrition 21; Orexigen Therapeutics, Inc.; Organon Pharmaceuticals; Osmotica; Otsuka Pharmaceuticals; Pamlab, LLC.; Pfizer Inc.; PharmaStar; Pharmavite LLC.; PharmoRx Therapeutics; Precision Human Biolaboratory; Prexa Pharmaceuticals, Inc.; PPD; Puretech Ventures; PsychoGenics; Psylin Neurosciences, Inc.; RCT Logic, LLC ( formerly Clinical Trials Solutions, LLC); Rexahn Pharmaceuticals, Inc.; Ridge Diagnostics, Inc.; Roche; Sanofi-Aventis US LLC.; Sepracor Inc.; Servier Laboratories; ScheringPlough Corporation; Shenox Pharmaceuticals; Solvay Pharmaceuticals, Inc.; Somaxon Pharmaceuticals, Inc.; Somerset Pharmaceuticals, Inc.; Sunovion Pharmaceuticals; Supernus Pharmaceuticals, Inc.; Synthelabo; Taisho Pharmaceutical; Takeda Pharmaceutical Company Limited; Tal Medical, Inc.; Tetragenex Pharmaceuticals, Inc.; TransForm Pharmaceuticals, Inc.; Transcept Pharmaceuticals, Inc.; Vanda Pharmaceuticals, Inc.; VistaGen; he has received speaking or publishing fees from Adamed, Co; Advanced Meeting Partners; American Psychiatric Association; American Society of Clinical Psychopharmacology; AstraZeneca; Belvoir Media Group; Boehringer Ingelheim GmbH; Bristol-Myers Squibb; Cephalon, Inc.; CME Institute/ Physicians Postgraduate Press, Inc.; Eli Lilly and Company; Forest Pharmaceuticals, Inc.; GlaxoSmithKline; Imedex, LLC; MGH Psychiatry Academy/Primedia; MGH Psychiatry Academy/Reed Elsevier; Novartis AG; Organon Pharmaceuticals; Pfizer Inc.; PharmaStar; United BioSource,Corp.; Wyeth-Ayerst Laboratories; he has equity holdings in Compellis and PsyBrain, Inc.; he has a patent for Sequential Parallel Comparison Design (SPCD), which are licensed by MGH to Pharmaceutical Product Development, LLC (PPD); and patent application for a combination of Ketamine plus Scopolamine in Major Depressive Disorder (MDD), licensed by MGH to Biohaven; and he receives copyright royalties for the MGH Cognitive \& Physical Functioning Questionnaire (CPFQ), Sexual Functioning Inventory (SFI), Antidepressant Treatment Response Questionnaire (ATRQ), Discontinuation-Emergent Signs \& Symptoms (DESS), Symptoms of Depression Questionnaire (SDQ), and SAFER; Lippincott, Williams \& Wilkins; Wolkers Kluwer; World Scientific Publishing Co. Pte.Ltd. In the past three years, Dr. Myrna Weissman received funding from the National Institute of Mental Health (NIMH), the National Institute on Drug Abuse (NIDA), the National Alliance for Research on Schizophrenia and Depression (NARSAD), the Sackler Foundation, the Templeton Foundation; and receives royalties from the Oxford University Press, Perseus Press, the American Psychiatric Association Press, and MultiHealth Systems. Dr. Madhukar H. Trivedi is or has been an advisor/consultant and received fee from (lifetime disclosure): Abbott Laboratories Inc., Akzo (Organon Pharmaceuticals Inc.), Allergan Sales LLC, Alkermes, Arcadia Pharmaceuticals Inc., AstraZeneca, Axon Advisors, Brintellix, Bristol-Myers Squibb Company, Cephalon Inc., Cerecor, Eli Lilly \& Company, Evotec, Fabre Kramer Pharmaceuticals Inc., Forest Pharmaceuticals, GlaxoSmithKline, Global Medical Education Inc., Health Research Associates, Johnson \& Johnson, Lundbeck, MedAvante Medscape, Medtronic, Merck, Mitsubishi Tanabe Pharma Development America Inc., MSI Methylation Sciences Inc., Nestle Health Science-PamLab Inc., Naurex, Neuronetics, One Carbon Therapeutics Ltd., Otsuka Pharmaceuticals, Pamlab, ParkeDavis Pharmaceuticals Inc., Pfizer Inc., PgxHealth, Phoenix Marketing Solutions, Rexahn Pharmaceuticals, Ridge Diagnostics, Roche Products Ltd., Sepracor, SHIRE Development, Sierra, SK Life and Science, Sunovion, Takeda, Tal Medical/Puretech Venture, Targacept, Transcept, VantagePoint, Vivus, and Wyeth-Ayerst Laboratories. In addition, he has received grants/research support from: Agency for Healthcare Research and Quality, Cyberonics Inc., National Alliance for Research in Schizophrenia and Depression, National Institute of Mental Health, National Institute on Drug Abuse, National Institute of Diabetes and Digestive and Kidney Diseases, Johnson \& Johnson; and he receives royalties from Janssen Research and Development LLC. All authors have approved this manuscript.

\section{Appendix A. Supplementary data}

Supplementary data related to this article can be found at http://dx. doi.org/10.1016/j.jpsychires.2018.04.003.

\section{References}

Altman, E.G., Hedeker, D., Peterson, J.L., Davis, J.M., 1997. The altman self-rating mania scale. Biol. Psychiatr. 42 (10), 948-955.

Bernstein, D.P., Stein, J.A., Newcomb, M.D., Walker, E., Pogge, D., Ahluvalia, T., Stokes, J., Handelsman, L., Medrano, M., Desmond, D., Zule, W., 2003. Development and validation of a brief screening version of the childhood trauma questionnaire. Child Abuse Negl. 27 (2), 169-190.

Chen, S., Yao, N., Qian, M., Lin, M., 2016. Attentional biases in high social anxiety using a flanker task. J. Behav. Ther. Exp. Psychiatr. 51, 27-34.

Cuthbert, B.N., 2014. The RDoC framework: facilitating transition from ICD/DSM to dimensional approaches that integrate neuroscience and psychopathology. World Psychiatr.: official journal of the World Psychiatric Association (WPA) 13 (1), 28-35.

Etkin, A., Schatzberg, A.F., 2011. Common abnormalities and disorder-specific compensation during implicit regulation of emotional processing in generalized anxiety and major depressive disorders. Am J Psychiatry 168 (9), 968-978.

Eysenck, M.W., Derakshan, N., Santos, R., Calvo, M.G., 2007. Anxiety and cognitive performance: attentional control theory. Emotion 7 (2), 336-353.

Farber, I.E., Spence, K.W., 1956. Effects of anxiety, stress, and task variables on reaction time. J. Pers. 25 (1), 1-18.

Fava, M., Rosenbaum, J.F., McCarthy, M., Pava, J., Steingard, R., Bless, E., 1991. Anger attacks in depressed outpatients and their response to fluoxetine. Psychopharmacol. Bull. 27 (3), 275-279.

Fava, M., Rush, A.J., Alpert, J.E., Balasubramani, G.K., Wisniewski, S.R., Carmin, C.N., Biggs, M.M., Zisook, S., Leuchter, A., Howland, R., Warden, D., Trivedi, M.H., 2008. Difference in treatment outcome in outpatients with anxious versus nonanxious depression: a STAR*D report. Am. J. Psychiatr. 165 (3), 342-351. 
First, M.B.S.R.L., Gibbson, M., Williams, J.B.W., 2002. Structured Clinical Interview for DSM-iv-tr Axis I Disorders, Research Version, Patient Edition with Psychotic Screen. Biometrics Research. New York State Psychiatric Institute New York.

Gameroff, M.J., Wickramaratne, P., Weissman, M.M., 2012. Testing the short and screener versions of the social adjustment scale-self-report (SAS-SR). Int. J. Meth. Psychiatr. Res. 21 (1), 52-65.

Gentes, E.L., Dennis, P.A., Kimbrel, N.A., Rissling, M.B., Beckham, J.C., Calhoun, P.S., 2014. DSM-5 posttraumatic stress disorder: factor structure and rates of diagnosis. J. Psychiatr. Res. 59, 60-67.

Hamilton, M., 1960. A rating scale for depression. J. Neurol. Neurosurg. Psychiatry 23, $56-62$.

Horn, J.L., 1965. A rationale and test for the number of factors in factor analysis. Psychometrika 30, 179-185.

Huyser, C., Veltman, D.J., Wolters, L.H., de Haan, E., Boer, F., 2011. Developmental aspects of error and high-conflict-related brain activity in pediatric obsessive-compulsive disorder: a fMRI study with a Flanker task before and after CBT. J. Child Psychol. Psychiatry Allied Discip. 52 (12), 1251-1260.

Insel, T., Cuthbert, B., Garvey, M., Heinssen, R., Pine, D.S., Quinn, K., Sanislow, C., Wang, P., 2010. Research domain criteria (RDoC): toward a new classification framework for research on mental disorders. Am. J. Psychiatr. 167 (7), 748-751.

Insel, T.R., Cuthbert, B.N., 2009. Endophenotypes: bridging genomic complexity and disorder heterogeneity. Biol. Psychiatr. 66 (11), 988-989.

Iza, M., Wall, M.M., Heimberg, R.G., Rodebaugh, T.L., Schneier, F.R., Liu, S.M., Blanco, C., 2014. Latent structure of social fears and social anxiety disorders. Psychol. Med. 44 (2), 361-370.

Kocovski, N.L., Endler, N.S., Cox, B.J., et al., 2004. The differential assessment of statetrait anxiety and depression in a clinically anxious sample. J. Psychopathol. Behav. Assess. 26 (3), 165-172.

Lang, P.J., Davis, M., Ohman, A., 2000. Fear and anxiety: animal models and human cognitive psychophysiology. J. Affect. Disord. 61 (3), 137-159.

McCrae, R.R., Costa, P.T., 2010. NEO Inventories for the NEO Personality Inventory-3 (NEO-pi-3), NEO Five-factor Inventory-3 (NEO-ffi-3), NEO Personality Inventory-revised (NEO-pi-r): Professional Manual PAR, Lutz, FL.

Meng, X.-L., Rosenthal, R., Rubin, D.B., 1992. Comparing correlated correlation coefficients. Psychol. Bull. 111, 172-175.

Nunnally, J.C., Bernstein, I.H., 1994. In: Psychometric Theory, third ed. McGraw-Hill, New York, NY.

O'Connor, B.P., 2000. SPSS and SAS programs for determining the number of components using parallel analysis and velicer's MAP test. Behav. Res. Methods Instrum. Comput. 32 (3), 396-402.

Robinson, O.J., Vytal, K., Cornwell, B.R., Grillon, C., 2013. The impact of anxiety upon cognition: perspectives from human threat of shock studies. Front. Hum. Neurosci. 7,
203

Rush, A.J., Trivedi, M.H., Ibrahim, H.M., Carmody, T.J., Arnow, B., Klein, D.N., Markowitz, J.C., Ninan, P.T., Kornstein, S., Manber, R., Thase, M.E., Kocsis, J.H., Keller, M.B., 2003. The 16-Item Quick Inventory of Depressive Symptomatology (QIDS), clinician rating (QIDS-C), and self-report (QIDS-SR): a psychometric evaluation in patients with chronic major depression. Biol. Psychiatr. 54 (5), 573-583.

Shear, M.K., Brown, T.A., Barlow, D.H., Money, R., Sholomskas, D.E., Woods, S.W., Gorman, J.M., Papp, L.A., 1997. Multicenter collaborative panic disorder severity scale. Am. J. Psychiatr. 154 (11), 1571-1575.

Snaith, R.P., Hamilton, M., Morley, S., Humayan, A., Hargreaves, D., Trigwell, P., 1995. A scale for the assessment of hedonic tone the Snaith-Hamilton Pleasure Scale. Br. J. Psychiatry 167 (1), 99-103.

Spielberger, C.D., Gorsuch, R.L., Lushene, R., Vagg, P.R., Jacobs, G.A., 1983. Manual for the State-trait Anxiety Inventory. Consulting Psychologists Press, Palo Alto, CA.

Spitzer, R.L., Kroenke, K., Williams, J.B., Lowe, B., 2006. A brief measure for assessing generalized anxiety disorder: the GAD-7. Arch. Intern. Med. 166 (10), 1092-1097.

Trivedi, M.H., McGrath, P.J., Fava, M., Parsey, R.V., Kurian, B.T., Phillips, M.L., Oquendo, M.A., Bruder, G., Pizzagalli, D., Toups, M., Cooper, C., Adams, P., Weyandt, S., Morris, D.W., Grannemann, B.D., Ogden, R.T., Buckner, R., McInnis, M., Kraemer, H.C., Petkova, E., Carmody, T.J., Weissman, M.M., 2016. Establishing moderators and biosignatures of antidepressant response in clinical care (EMBARC): rationale and design. J. Psychiatr. Res. 78, 11-23.

Trivedi, M.H., Wisniewski, S.R., Morris, D.W., Fava, M., Gollan, J.K., Warden, D. Nierenberg, A.A., Gaynes, B.N., Husain, M.M., Luther, J.F., Zisook, S., Rush, A.J., 2011a. Concise Health Risk Tracking scale: a brief self-report and clinician rating of suicidal risk. J. Clin. Psychiatr. 72 (6), 757-764.

Trivedi, M.H., Wisniewski, S.R., Morris, D.W., Fava, M., Kurian, B.T., Gollan, J.K Nierenberg, A.A., Warden, D., Gaynes, B.N., Luther, J.F., Rush, A.J., 2011b. Concise Associated Symptoms Tracking scale: a brief self-report and clinician rating of symptoms associated with suicidality. J. Clin. Psychiatr. 72 (6), 765-774.

Velicer, W.F., 1976. Determining the number of components from the matrix of partial correlations. Psychometrika 41, 321-327.

Wardenaar, K.J., van Veen, T., Giltay, E.J., de Beurs, E., Penninx, B.W., Zitman, F.G., 2010. Development and validation of a 30-item short adaptation of the mood and anxiety symptoms questionnaire (MASQ). Psychiatr. Res. 179 (1), 101-106.

Webb, C.A., Dillon, D.G., Pechtel, P., Goer, F.K., Murray, L., Huys, Q.J., Fava, M., McGrath, P.J., Weissman, M., Parsey, R., Kurian, B.T., Adams, P., Weyandt, S., Trombello, J.M., Grannemann, B., Cooper, C.M., Deldin, P., Tenke, C., Trivedi, M. Bruder, G., Pizzagalli, D.A., 2016. Neural correlates of three promising endophenotypes of depression: evidence from the EMBARC study.

Neuropsychopharmacology 41 (2), 454-463. 